\title{
Chest CT based Viral Pneumonia Imaging Reporting and Data System (VP-RADS): experiences of COVID-19 in Ningbo, China
}

\author{
Jianjun Zheng ${ }^{1,2 \#}$, Jingfeng Zhang ${ }^{1,2 \#}$, Kun Yan ${ }^{1}$, Qi Dai ${ }^{1}$, Jie Lin ${ }^{1}$, Hongbin Zhang ${ }^{1}$, Bibo Hu ${ }^{1}$, Bin Chen ${ }^{1}$, \\ Ting Cai ${ }^{1,2}$
}

${ }^{1}$ Hwa Mei Hospital, University of Chinese Academy of Sciences, Ningbo, China; ${ }^{2}$ Institute of Life and Health Industry, University of Chinese Academy of Sciences, Ningbo, China

"These authors contributed equally to this work.

Correspondence to: Jianjun Zheng. Hwa Mei Hospital, University of Chinese Academy of Sciences, No. 41, Xibei Str, Haishu District, Ningbo 315010 , China. Email: zhengjianjun@ucas.ac.cn.

Provenance and Peer Review: This article was a free submission to the journal. The article was sent for external peer review organized by the editorial office.

Submitted Apr 20, 2020. Accepted for publication Jun 05, 2020.

doi: 10.21037 /qims-20-587

View this article at: http://dx.doi.org/10.21037/qims-20-587

\section{Introduction}

In December 2019, a novel coronavirus pneumonia emerged in Wuhan, Hubei, China, and spread rapidly over the world (1). On January 20, 2020, China included the disease as a Class B infectious disease under the Law of the People's Republic of China on the Prevention and Control of Infectious Diseases, with prevention and control measures for Class A (highest level) infectious diseases (2). On February 11, 2020, the virus which caused the epidemic was officially named as severe acute respiratory syndrome coronavirus 2 (SARS-CoV-2) by the International Committee on Taxonomy of Viruses. On the same day, the disease caused by SARS-CoV-2 was named as coronavirus disease 2019 (COVID-19) by the World Health Organization (WHO) (3).

In February 2020, the Chinese Society of Radiology issued "a recommendation for Radiological Diagnosis of COVID-19 Pneumonia (first edition)", in which the radiological examination protocol, imaging findings, staging and evolutions were stated, the essential roles of radiology in the diagnosis (suspected and clinically confirmed cases), patient follow-up and discharge were highlighted (4). Due to its easy availability, chest CT is emerging with significant advantages in implementing "early detection, early reporting, early isolation, early diagnosis, and early treatment" measures of COVID-19 control (5). However, there is still a lack of unified understanding and standards on CT based COVID-19 probability classification nor an objective and quantifiable interpretation of the result.

By adopting a series of aggressive prevention and control measures (6-8), the epidemic situation of COVID-19 in Ningbo, Zhejiang Province, China, has been effectively curbed. However, the city epidemic control is now challenged with the overall work resumption and the ongoing immigration (imported) cases. Therefore, aiming to provide a guidance for disease prevention and treatment at various medical institutions, and to generate a standardized radiological diagnosis, this "chest CT based Viral Pneumonia Imaging Reporting and Data System (VP-RADS)" was initiated by radiology experts from the designated hospital for COVID-19 control in Ningbo, i.e., Hwa Mei Hospital, University of Chinese Academy of Sciences, and Ningbo Society of Radiology.

\section{Background of VP-RADS 1.0}

In recent years, the world has witnessed several major infectious diseases outbreaks, such as Severe Acute Respiratory Syndrome (SARS), Middle East Respiratory Syndrome (MERS), avian influenza A (H7N9) and COVID-19, all of which caused by viruses and posted a 
great threat to human life and health $(9,10)$. A common character in major respiratory infectious disease is pulmonary inflammation. For COVID-19, nucleic acid testing and virus gene sequencing are recognized as the gold standard (11). The accuracy of SARS-CoV-2 testing has not been systematically evaluated, and the sensitivity of testing likely depends on the precision of RT-PCR assay, the type of specimen obtained, and the quality of specimen. In a study of 51 patients who were hospitalized in China with fever or acute respiratory symptoms and ultimately had a positive SARS-CoV-2 RT-PCR test (mainly on throat swabs), 15 patients (29\%) had a negative initial test and only were diagnosed by serial testing (12). In a similar study of 70 patients in Singapore, initial nasopharyngeal testing was negative in 8 patients (11\%) (13). In addition, the sensitivity of SARS-CoV-2 testing is related to the duration of illness at the time of testing (14). Recently, some studies suggested that chest CT could be a supplemental screening or diagnostic tool for COVID-19 in epidemic area and found the positive rate of chest CT scan was $86.2-98 \%$ in patients on the first visit $(15,16)$. However, the positive rate of chest CT scan in asymptomatic COVID-19 cases or COVID-19 cases with mild symptoms might be much lower $(17,18)$.

VP-RADS 1.0 is a classification system of CT imaging reporting on acute pulmonary exudative lesions, which is dedicated for a standardization on diagnostic reporting, risk classification, and providing imaging evidences for the epidemic containment. The benefits of VP-RADS 1.0 are as the following: (I) standardizing the radiologist's recognition of acute pulmonary exudative lesions suggested by CT images and the estimation of patients' risk of contracting COVID-19; (II) reducing the variation and uncertainty of clinicians' interpretation of a chest CT report, narrowing the knowledge gap between radiologists and clinicians; (III) providing the basis for risk classification and patient triage to optimize the protocol of epidemic prevention and treatment in medical institutions and reduce the incidence of nosocomial infections.

\section{VP-RADS 1.0 fundamental}

All acute pulmonary exudative lesions are objectively and effectively categorized, incorporating CT imaging features, epidemiology history, clinical manifestations and laboratory findings to determine the likelihood of COVID-19.

\section{VP-RADS 1.0 lexicon}

VP-RADS 1.0 consists of five categories including 12 indicators, covering epidemiological history, clinical manifestations, chest imaging, clinical exclusion items, pathogenic or serological basis of COVID-19 pneumonia. Low-dose CT (LDCT) scan mode should be used in the radiological follow-up and clinical screening. Historically, standard dose chest CT was superior for the detection of subtle ground-glass opacities (GGOs) as compared to low-dose technique (19). With the advent of iterative reconstruction algorithms to reduce the visibility of image noise and maintain image quality, low-dose chest CT is appropriate in assessing GGOs $(20,21)$.

\section{Epidemiological history}

* History of travel to or residence in epidemic areas, or in other communities where cases have been reported within 14 days prior to the onset of the disease;

* In contact with SARS-CoV-2 infected individuals (with positive results of the nucleic acid testing) within 14 days prior to the onset of the disease;

- In contact with patients who have fever or respiratory symptoms from epidemic areas, or from communities where confirmed cases have been reported within 14 days before the onset of the disease;

* Clustered cases (2 or more cases with fever and/or respiratory symptoms in a small area such as families, offices, schools, etc. within 2 weeks).

\section{Clinical manifestations}

* Fever and/or respiratory symptoms;

* Normal or decreased WBC count, normal or decreased lymphocyte count in the early stage of onset.

\section{Chest imaging findings}

* CT imaging indicates acute pulmonary exudative lesions, usually showing small patchy GGOs and interstitial changes in the early stage, infiltration and consolidation in the progressive stage. Typical imaging findings are characterized with scattered GGO involving multiple lobes in a non-anatomic pattern and more apparent in the peripheral zone of lungs $(22,23)$.

\section{Clinical exclusion}

* Clear clinical evidence of bacterial pneumonia or other pathogens; 
* Unchanged GGOs or consolidation for the past two weeks (although this kind of imaging findings are helpful to exclude COVID-19 lesions, COVID-19 diagnosis can't be excluded for this patient).

\section{Pathogenic and serological evidences}

* Real-time fluorescent RT-PCR indicates positive for SARS-CoV-2 nucleic acid;

* Viral gene sequence is highly homologous to known novel coronaviruses;

* Specific IgM and IgG of SARS-CoV-2 are detectable in serum; specific IgG of SARS-CoV-2 is detectable or reaches a titration of at least 4-fold increase during convalescence compared with the acute stage.

\section{Classification of VP-RADS 1.0}

Assessed with the indicators above, patient risk of contracting COVID-19 is classified into five categories (category $0,1,2,3,4)$. The follow-up CT scan of a confirmed case is labeled as COVID-19 F (Covid-19 follow-up). The detailed categories are as following (Table 1).

\section{VP-RADS category 0}

\section{Definition}

Chest CT imaging cannot be fully recognized or assessed (Figure 1), classified as uncertain category.

\section{Imaging reporting and recommendations}

If the partial or a full lung cannot be evaluated due to artifacts, CT technicians should determine immediately whether an additional scan is necessary. For conditions that artifacts cannot be eliminated, an explanation should be presented in the CT report.

\section{VP-RADS category 1}

\section{Definition}

No acute pulmonary exudative changes detected on chest CT (Figure 2).

\section{Suggestions for clinical management}

One should note that a VP-RADS category 1 is not a definite exclusion for COVID-19. Further investigations and treatment should be determined according to the epidemiological history and clinical manifestations.

\section{Reporting and recommendations}

Considering the time interval between disease onset and CT imaging findings, we should constantly keep an eye on patients with confirmed epidemiological history and clinical manifestations, and a short-term follow up should be suggested in the report. Notably, GGOs without any changes for over 2 weeks should be classified as VP-RADS category 1 (Figure 2C,D,E,F).

\section{VP-RADS category 2}

\section{Definition}

Acute pulmonary exudation is found on chest CT scan. Combined with clinical manifestations, COVID-19 contraction can be excluded in most cases (Figure 3).

\section{Suggestions for clinical management}

Appropriate measures should be taken on the basis of etiology, other screening items and a recent chest LDCT should be considered. Most of VP-RADS category 2 cases are consequences of the following two types of lesions: (I) the acute exudation is limited in a single lobe or segment. Yellow sputum and a blood test showing bacterial infection are found at the first visit. (II) There are distinct clinical etiologies for the acute exudation, such as pulmonary edema, pulmonary hemorrhage, pulmonary contusion, pulmonary infarction, radioactive pneumonia, etc. At this situation, epidemiological history is regarded as a secondary indicator.

\section{Reporting and recommendations}

An anatomical pattern of the acute exudation on chest CT should be noted, and clinical manifestations and laboratory findings should be taken into account. A VP-RADS category 2 with an explicit etiological diagnosis would be appropriate for those with evident bacterial pneumonia or etiology. A follow-up of chest LDCT is recommended after treatment.

\section{VP-RADS category 3}

\section{Definition}

Acute pulmonary exudation is found on chest CT scan without known COVID-19 epidemiological history. However, COVID-19 cannot be excluded according to imaging findings and clinical manifestations (Figure 4).

\section{Suggestions for clinical management}

During the epidemic outbreak, a VP-RADS category 3 
Table 1 Description of VP-RADS Classification (COVID-19 Version) and diagnostic \& therapeutic suggestions

\begin{tabular}{|c|c|c|c|c|}
\hline VP-RADS & Definition & Indicator & $\begin{array}{l}\text { Imaging reporting and } \\
\text { recommendations }\end{array}$ & $\begin{array}{l}\text { Suggestions for clinical } \\
\text { management }\end{array}$ \\
\hline Category 0 & $\begin{array}{l}\text { Cannot be } \\
\text { classified, } \\
\text { defined as } \\
\text { uncertain } \\
\text { category }\end{array}$ & $\begin{array}{l}\text { CT images cannot be fully } \\
\text { recognized or assessed }\end{array}$ & $\begin{array}{l}\text { Technicians should determine } \\
\text { immediately whether an additional } \\
\text { scan is necessary. For conditions } \\
\text { that artifacts cannot be eliminated, } \\
\text { an explanation should be } \\
\text { presented in the CT report }\end{array}$ & None \\
\hline Category 1 & $\begin{array}{l}\text { cannot be } \\
\text { excluded } \\
\text { definitely for } \\
\text { COVID-19 }\end{array}$ & $\begin{array}{l}\text { (I) No acute pulmonary exudative } \\
\text { changes detected on chest CT. (II) } \\
\text { Ground-glass opacities without any } \\
\text { changes for over } 2 \text { weeks }\end{array}$ & $\begin{array}{l}\text { If epidemiological history of } \\
\text { COVID-19 is confirmed, short-term } \\
\text { follow-up should be recommended } \\
\text { in the report }\end{array}$ & $\begin{array}{l}\text { Further investigations and } \\
\text { treatment should be determined } \\
\text { according to the } \\
\text { epidemiological history and } \\
\text { clinical manifestations }\end{array}$ \\
\hline Category 3 & $\begin{array}{l}\text { COVID-19 } \\
\text { cannot be } \\
\text { excluded }\end{array}$ & $\begin{array}{l}\text { Acute pulmonary exudation is found } \\
\text { on chest CT without typical imaging } \\
\text { findings, without known COVID-19 } \\
\text { epidemiological history, and with } \\
\text { clear clinical evidences for bacterial } \\
\text { pneumonia or other definite } \\
\text { pathogenic factors }\end{array}$ & $\begin{array}{l}\text { The reporting should be included in } \\
\text { hospital critical values for a timely } \\
\text { react, expertise consultation and a } \\
\text { LDCT recheck }\end{array}$ & $\begin{array}{l}\text { During the epidemic outbreak, } \\
\text { a VP-RADS category } 3 \text { patient } \\
\text { should receive an emergency } \\
\text { consultation by clinical } \\
\text { specialists, and the subsequent } \\
\text { screening and treatment could } \\
\text { be determined afterwards }\end{array}$ \\
\hline
\end{tabular}

LDCT, low-dose CT.

patient should receive an emergency consultation by clinical specialists, and the subsequent screening and treatment could be determined afterwards. One should note that a VPRADS category 3 should be a comprehensive perception after a thorough reviewing of CT imaging and clinical evidences, and no specific etiology nor epidemiological history. Timely detection of virus specific antibody, RTPCR and common respiratory pathogens are imperative. LDCT follow-up is recommended.

\section{Reporting and recommendations}

All the following conditions are indispensable for the identification of VP-RADS category 3: (I) imaging findings suggest neither bacterial pneumonia nor COVID-19, which is characterized with scattered GGOs involving multiple lobes in a non-anatomic pattern and more apparent in the peripheral zone of lungs; (II) no clear clinical evidences for bacterial pneumonia or other definite pathogenic factors; (III) no epidemiological history. The hospital should 


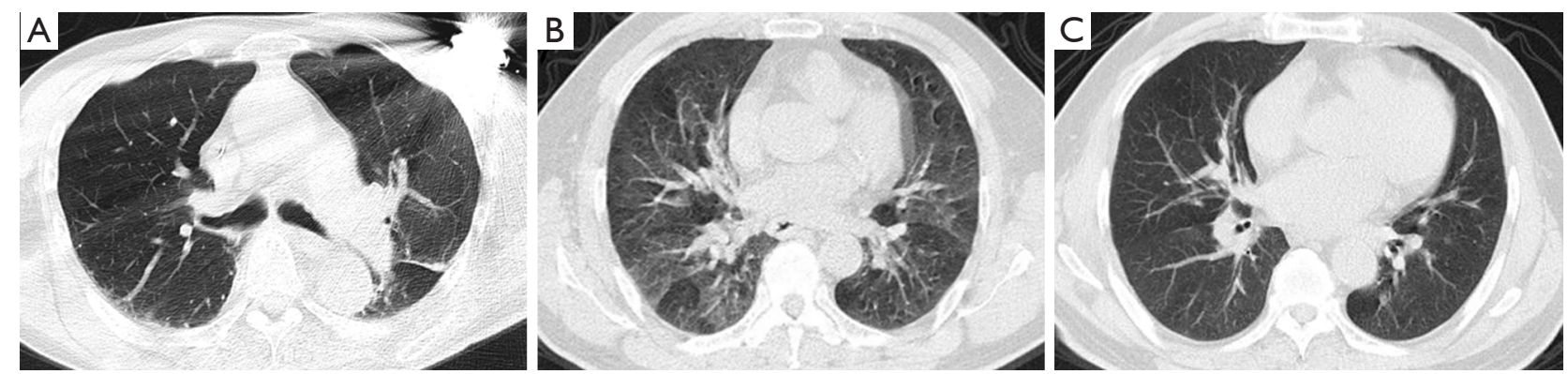

Figure 1 Illustration of VP-RADS category 0. (A) Chest CT images reveal metal artifacts caused by pacemaker. The image cannot be evaluated comprehensively. (B,C) A 68-year-old man had a cough for four days. Because of lung motion artifacts caused by coughing, chest CT shows multiple ground-glass opacities in bilateral lungs, radiologist cannot evaluate the condition comprehensively (B). Images were evaluated immediately by the technician, so repeat CT scan was performed after breath training, and no lesion was found (C).

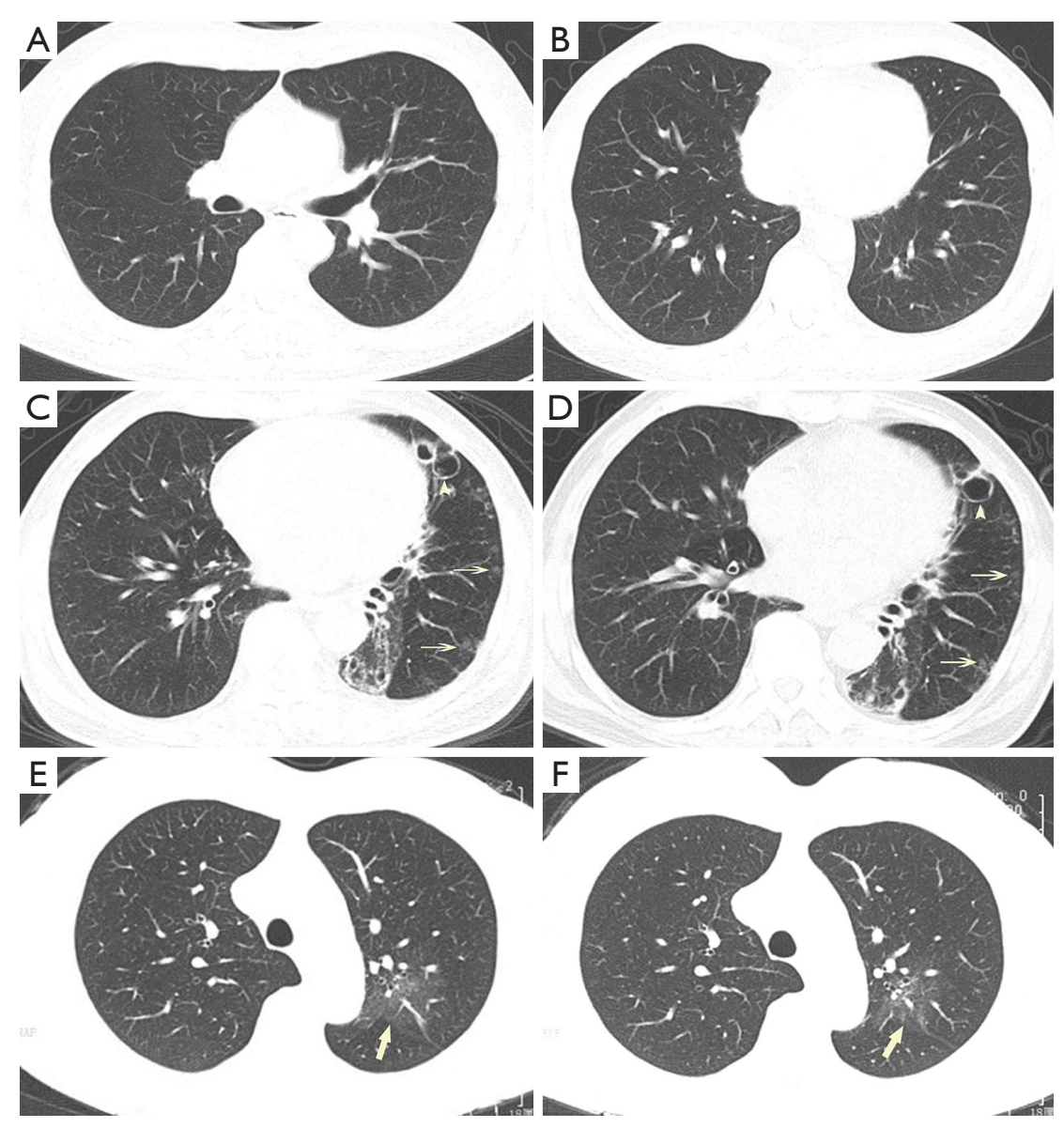

Figure 2 Illustration of VP-RADS category 1. (A,B) A 57-year-old man with close contact history of COVID-19 patient had a fever for half a day, and normal range of blood routine test was found. Findings on chest CT images are normal. (C,D) A 58-year-old male with bronchiectasis (arrowhead) for more than 10 years had a low fever and a cough for 6 days. He denied epidemiological contact history with COVID-19 patient. Chest CT images show multiple ground-glass opacities in the subpleural area of left lower lobe (C, arrow). Compared with the CT images one year ago, there are no significant changes in the left lung (D, arrow). (E,F) A 69-year-old female had a cough for 2 days without any epidemiological contact history of COVID-19 patient. Chest CT images show ground-glass opacities in the left upper lobe (E, arrow). Compared with the CT images two years ago, there are no significant changes (F, arrow). 


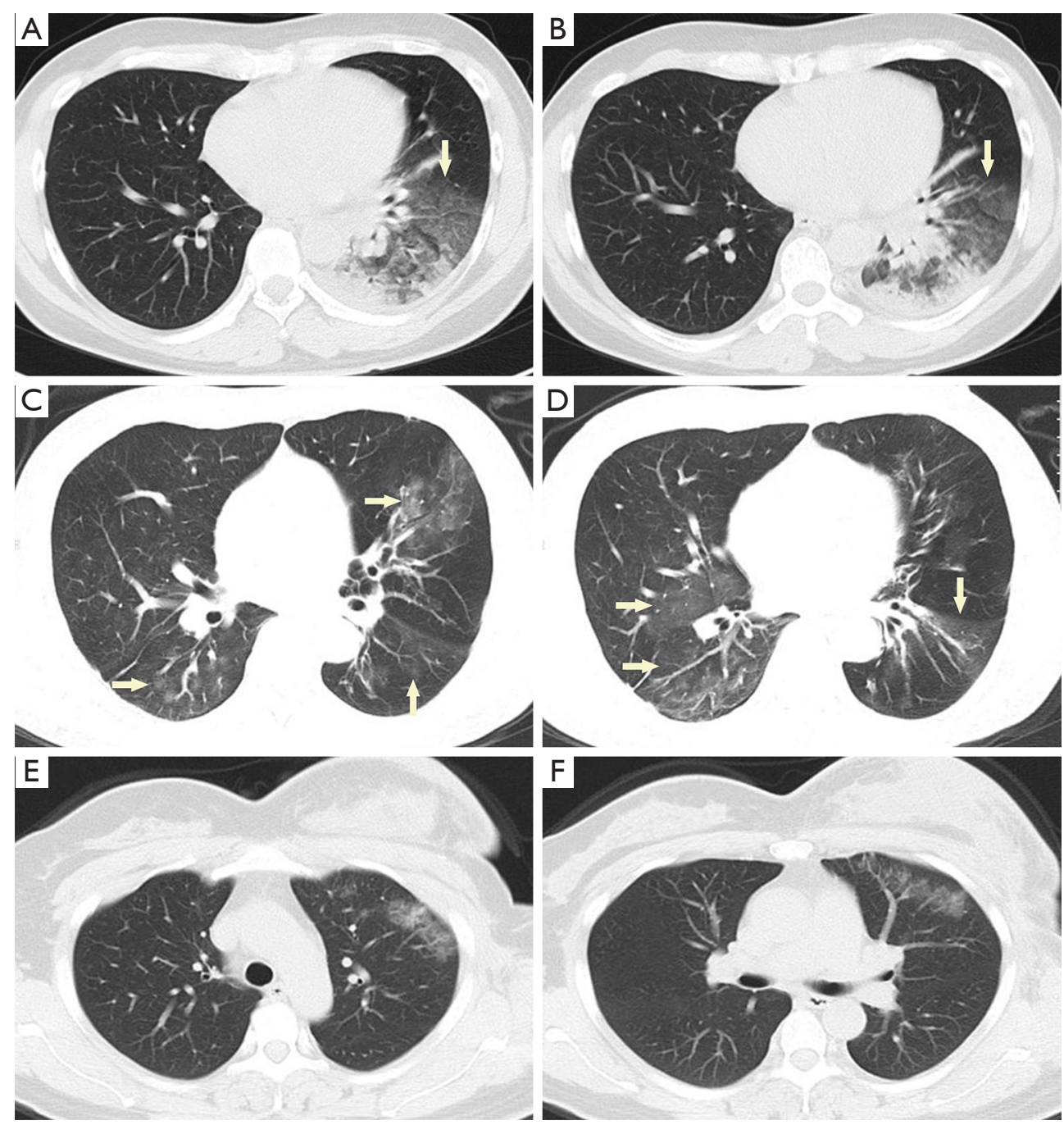

Figure 3 Illustration of VP-RADS category 2. (A,B) A 36-year-old male had a fever and cough with yellow sputum for three days. He denied epidemiological contact history with COVID-19 patient. Blood routine test showed: WBC $8.2 \times 10^{9} / \mathrm{L}$, leukomonocyte $1.0 \times 10^{9} / \mathrm{L}(11.8 \%)$, neutrophil granulocyte $6.8 \times 10^{9} / \mathrm{L}(82.7 \%)$; hypersensitive $\mathrm{C}$ reactive protein $(\mathrm{CRP}) 89.73 \mathrm{mg} / \mathrm{L}$. Chest CT shows irregular ground-glass opacities with partial consolidation in an anatomic pattern in the left lower lobe (arrow). The patient was diagnosed as lobar pneumonia. (C,D) A 47-year-old male had a cough and hemoptysis for four days. He denied epidemiological contact history with COVID-19 patient. Chest CT images show multiple ground-glass opacities in both lungs (arrows). The patient was diagnosed as bronchiectasis. (E,F) A 45-year-old female was re-examined after breast conserving surgery due to left breast cancer, and was performed radiotherapy 3 months ago. She had a cough occasionally without fever, and denied epidemiological contact history with COVID-19 patient. Blood routine test is in a normal range. Chest CT shows multiple ground-glass opacities in the subpleural area of left upper lobe, the margin of the focus was straight, consistent with the radiation field. The patient was diagnosed as radiation induced pneumonia.

maintain highest vigilance for VP-RADS category 3 cases, and the reporting should be included in hospital critical lists for a timely react, expertise consultation and a LDCT recheck.

\section{VP-RADS category 4}

\section{Definition}

Acute pulmonary exudation is found in chest CT scan, with known COVID-19 epidemiological history and clinical 


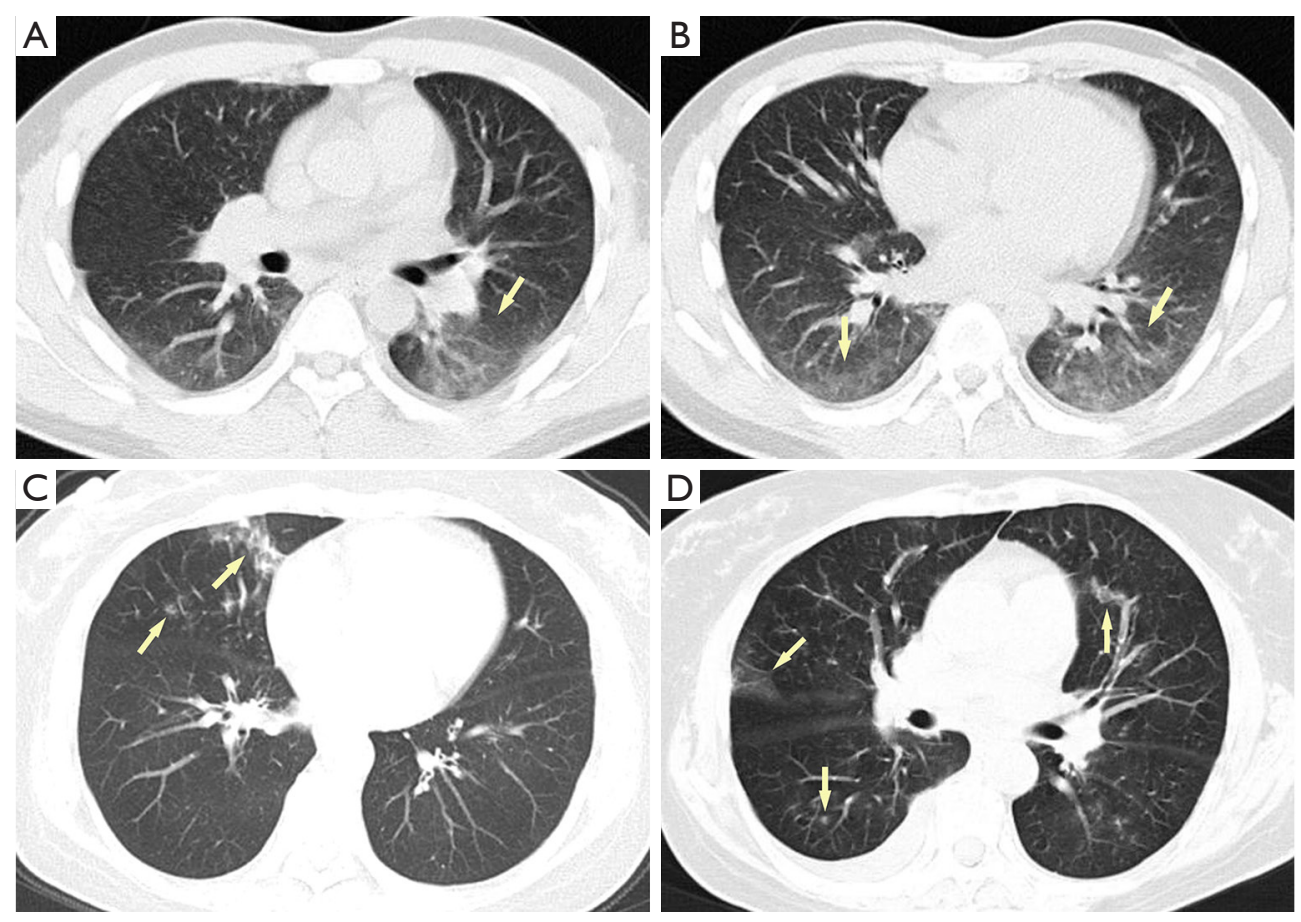

Figure 4 Illustration of VP-RADS category 3. (A,B) A 23-year-old male had a fever for four days. He denied epidemiological contact history with COVID-19 patient. Chest CT images show multiple ill-defined ground-glass opacities in the lower lobe of bilateral lungs (arrows). The patient was diagnosed as influenza A. (C,D) A 66-year-old female had a fever and cough for seven days. He denied epidemiological contact history with COVID-19 patient. Chest CT images show multiple ground-glass opacities in bilateral lungs, and partial consolidation in the right middle lobe (arrows). The patient was diagnosed as COVID-19.

manifestations, suggesting a high possibility of COVID-19 (Figure 5).

\section{Suggestions for clinical management}

During the epidemic outbreak, a VP-RADS category 4 confirmation should activate hospital prevention and treatment expert group for an immediate multi-disciplinary consultation, and take measures afterwards.

\section{Reporting and recommendations}

During the epidemic outbreak, an acute pulmonary exudation, combined with any of the following would confirm a VP-RADS category 4: (I) there is a definite epidemiological history without clinical evidence for bacterial pneumonia or other etiology; (II) there are imaging characteristics of COVID-19, with or without epidemiological evidence.

Once VP-RADS category 4 is identified, critical values reporting protocols must be adhered and hospital emergency response for prevention and control should be initiated.

\section{COVID-19 F}

\section{Definition}

Follow-up of confirmed COVID-19 cases.

\section{Suggestions for clinical management}

There should be a continuous assessment on therapeutic effect in confirmed cases. A chest CT scan can provide imaging evidences for the treatment especially when patient condition changes.

\section{Reporting and recommendations}

Radiologists should be proficient in the classification system, and give an objective assessment on the treatment effect, including disease progression, extensive consolidation (white lung), no significant changes, partial absorption and completely resolved (Figure 6), as well as detection of complications and other secondary diseases. When 


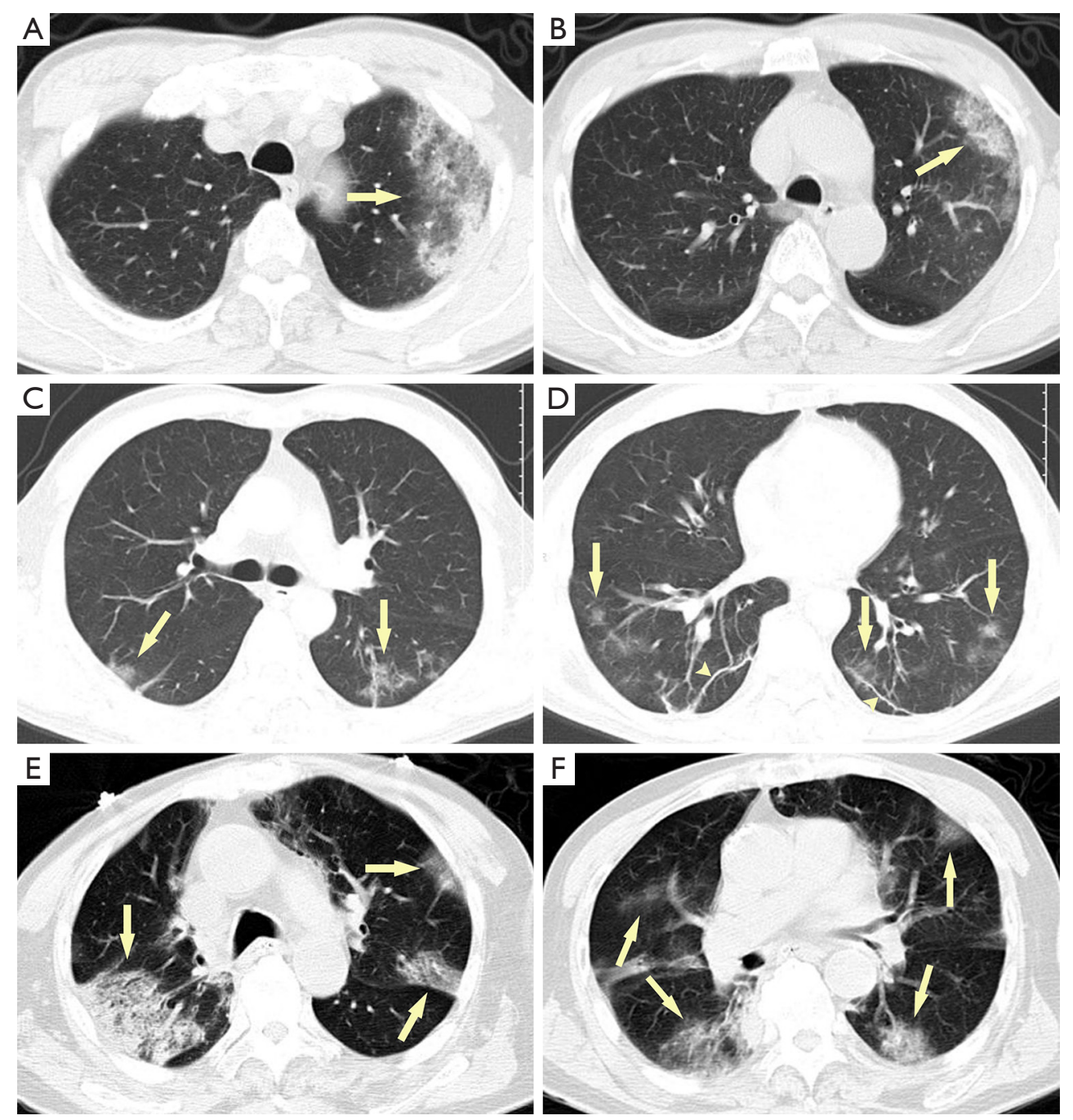

Figure 5 Illustration of VP-RADS category 4. (A,B) A 56-year-old male with close contact history of COVID-19 patient had a headache for four days and got a fever for one day. At the first visit, chest CT shows irregular ground-glass opacities with partial consolidation in the subpleural area of left upper lobe (arrow). Throat swab sample was tested positive for SARS-CoV-2 nucleic acid, and the patient was diagnosed as COVID-19. (C,D) A 54-year-old male had a fever and cough for ten days. At the first visit, chest CT shows multiple ill-defined ground-glass opacities (arrows) with local linear changes (arrowhead) in a non-anatomical pattern in the subpleural area of bilateral lungs. The samples were tested negative for SARS-CoV-2 on RT-PCR assay until the 8th time, then the patient was diagnosed as COVID-19. (E,F) A 71-year-old male complained of breath shortness for four days and fever for one day. Chest CT shows multiple ground-glass opacities with partial consolidation in an anatomical pattern in the subpleural area of bilateral lungs (arrows). In February 2019, the patient was diagnosed as viral pneumonia caused by influenza $\mathrm{H} 1 \mathrm{~N} 1$ virus.

chest imaging shows obvious lesion progression within 24-48 hours $>50 \%$, the patient shall be managed as a severe case (11). Moreover, considering the high radiation of CT, serial chest radiography may be taken in the places of CT for monitoring disease regression or progression of severe or critical COVID-19 cases on clinical demand $(24,25)$.

\section{Notes for VP-RADS 1.0 application}

(I) VP-RADS categories 1 and 2 are defined as negative chest CT results, while VP-RADS categories 3 and 4 as positive chest CT results for viral pneumonia. However, a negative result is no definite exclusion of COVID-19 (18). An epidemiological history and 


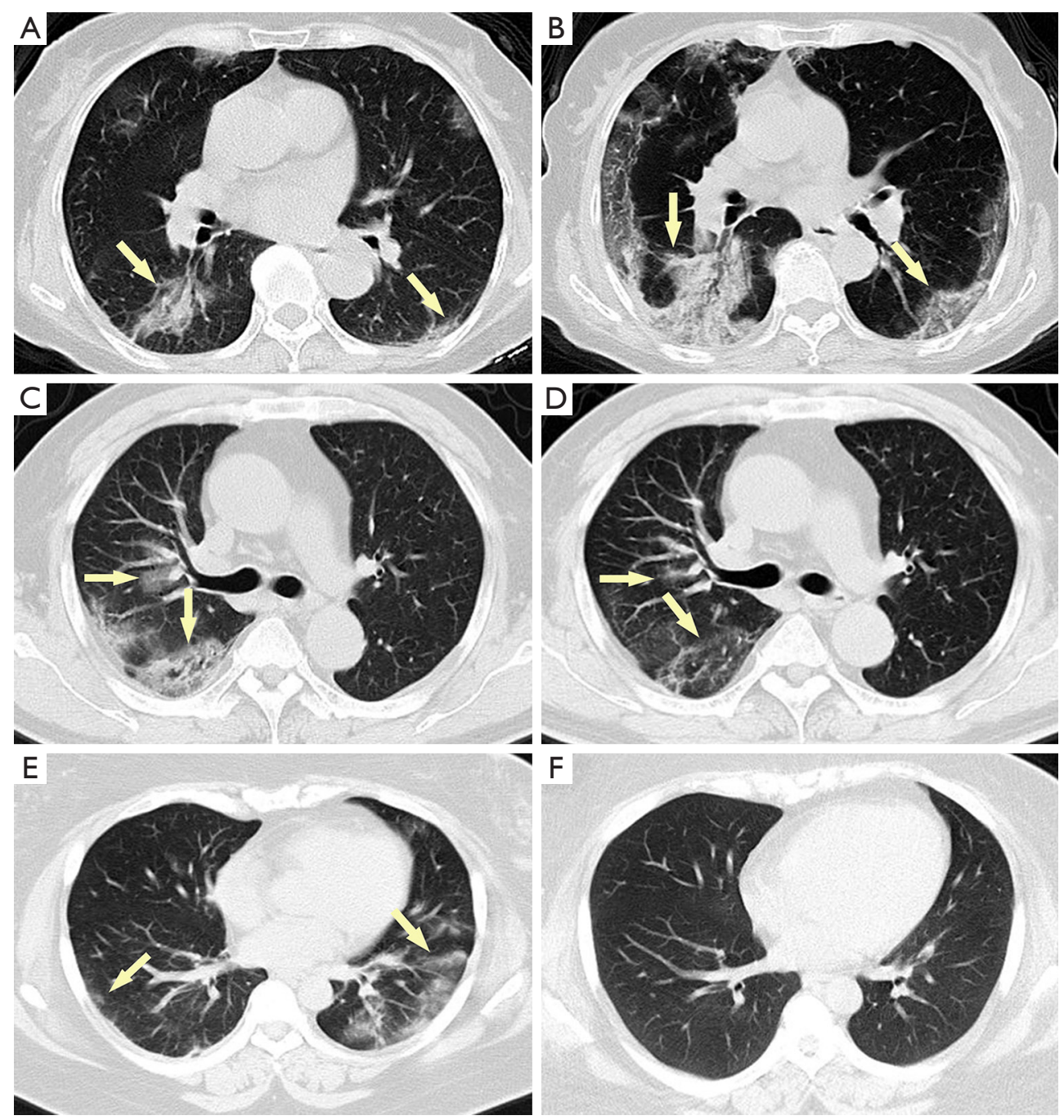

Figure 6 Illustration of COVID-19 F. (A,B) Progressive stage, a 70-year-old female diagnosed as COVID-19. Chest CT scan on 29 January, 2020 shows multiple ground-glass opacities in bilateral lungs (A, arrows). During treatment, repeat CT scan on 2 February, 2020 reveals increasing number of lesions obviously, enlarged areas and partially fusion (B, arrows). (C,D) Obvious absorption, a 65-year-old male diagnosed as COVID-19. Chest CT scan on 31 January, 2020 shows multiple ground-glass opacities with partial consolidation in the right lung (C, arrows). During treatment, repeat CT scan on 4 February, 2020 shows lesions were absorbed obviously with a small amount of residual linear opacities (D, arrows). (E,F) Complete absorption, a 34-year-old female diagnosed as COVID-19. Chest CT scan on 7 February, 2020 shows multiple ground-glass opacities in bilateral lungs (E, arrows). With the treatment accomplished, repeat CT on 2 March, 2020 shows lesions were resolved completely (F).

clinical manifestations should both be taken into account in clinical screening.

(II) In the early stage of COVID-19, chest CT images show multiple GGOs and interstitial changes. The thin-section CT (1-2 $\mathrm{mm}$ ) reconstruction and lung window observation are necessary for confirmation.

(III) When interpreting images, a comprehensive decision-making logic is necessary for a rational analysis, considering epidemiological history, clinical manifestations, laboratory tests and other relevant data.

(IV) In the epidemic outbreak, the principle of "early detection, early reporting, early isolation, early diagnosis, early treatment" should always be followed. 
The first diagnosis of the imaging should be the VPRADS classification, in order to optimize clinician understanding and risk estimation, which eventually could facilitate the epidemic containment and clinical treatment.

(V) Respiratory infectious diseases tend to be more active in winter and spring. For VP-RADS category 2 cases, it is necessary to test the common respiratory pathogens before clinical treatment; for VP-RADS category 3 cases, a virus-specific antibody and/or nucleic acid test should be provided timely, as well as tests on common respiratory pathogens before etiological treatment; for VP-RADS category 4 cases, consecutive viral specific antibody and nucleic acid tests should be performed.

\section{VP-RADS critical in epidemic prevention and treatment}

\section{The definition of VP-RADS critical}

(I) Given that SARS-CoV-2 has very high transmissibility (26), we include VP-RADS category 3 and VP-RADS category 4 as critical, for an efficient management of high-risk patients and to minimize patient gathering, uncontrolled mobilization and nosocomial infection.

(II) System Inflammatory Reaction Syndrome may be the reason for the sudden deterioration in some COVID-19 patients (27). Therefore, for a timely clinical treatment, disease progression, diffused consolidation (white lung) and other possible critical conditions found on follow-up should also be included in the criticals.

\section{Precise engagement of radiological examination and critical value reporting}

In the epidemic outbreak, all designated medical institutions of epidemic prevention and treatment should take "interval time between chest CT application and the diagnostic results completed" as a hospital-level patient safety indicator. We implemented the principle of "realtime imaging reading, oral reporting first". In this way, we successfully shortened the time from outpatient reception to observation or isolation, and putting forward the hospital epidemic prevention and control $(5,8)$.

\section{Limitations and expectations of VP-RADS 1.0}

The imaging manifestations of COVID-19 are diverse on chest CT, with acute pulmonary exudation and interstitial changes being the main features (28). GGOs, consolidation, linear opacities in the pulmonary peripheral area are the predominant imaging findings of COVID19. However, they are not exclusive in COVID-19, bacterial, mycoplasma, chlamydia, and other viral pneumonia may have similar imaging changes (29). Meanwhile, there is a time interval between radiological changes and symptom onset and nucleic acid results in some cases.

Despite the shortcoming, we believe up until now VPRADS 1.0 is an important documentation for a standardized imaging diagnosis and reports. The employment of the system makes it possible to objectively assess the patient's COVID-19 risk, and to quickly issue critical reports for timely epidemic containment. VP-RADS helps to set up triage in waiting areas, and is able to recognize highrisk patient and severe cases efficiently, leading to well deployment of medical resources.

The knowledge on imaging evolution of COVID-19 is still in need of more data to evaluate; meanwhile, we are also challenged with certain problems raised upon, including potential risk of cross-infection, radiation hazards by CT scans, the false positive and false negative results, all of which are worth further exploring and investigating.

\section{Acknowledgments}

We would like to pay sincere tribute to all medical staff fighting the epidemic. For the consensus drafting, we would like to give special appreciation to the strong support from the following teams in Hwa Mei Hospital, University of Chinese Academy of Sciences: Epidemic Control and Prevention Leading Group, Radiology Dept., Fever Clinics, Observation Wards, Isolation Wards, Hospital InfectionControl Dept, Medicine Dept., Nursing Dept., Center of Discipline Development, etc. In addition, we would like to thank the following postgraduate students (Yufen Wang, Ruirui Liu, Yangfan Zhang, whose major is imaging medicine and nuclear medicine, School of Medicine, Ningbo University) and undergraduates (Liuqiong Yang, majoring in medical imaging, Wenzhou Medical University) for their assistance. We are very appreciated with Dr. Zhang Chen for polishing this article. Despite having been discussed repeatedly, it is inevitable that there are some 
deficiencies in the document. We hope that our colleagues will put forward suggestions for this document to improve practice and application, so to make the future versions of the VP-RADS more comprehensive and practical.

Funding: This study was supported by Key Research Foundation of Hwa Mei Hospital, University of Chinese Academy of Sciences, China (Grant No. 2020HMZD19 and No. 2020HMZD20).

\section{Footnote}

Conflict of Interest: All authors have completed the ICMJE uniform disclosure form (available at http://dx.doi. org/10.21037/qims-20-587). The authors have no conflicts of interest to declare.

Ethical Statement: Our article is permitted by our ethics committee named "Ethics Committee for Human Research of Hwa Mei Hospital, University of Chinese Academy of Sciences". The ID is PJ-NBEY-KY-2020-030-01. Our research doesn't require consent from participants because it is a retrospective study.

Open Access Statement: This is an Open Access article distributed in accordance with the Creative Commons Attribution-NonCommercial-NoDerivs 4.0 International License (CC BY-NC-ND 4.0), which permits the noncommercial replication and distribution of the article with the strict proviso that no changes or edits are made and the original work is properly cited (including links to both the formal publication through the relevant DOI and the license). See: https://creativecommons.org/licenses/by-nc-nd/4.0/.

\section{References}

1. Hui DS, I Azhar E, Madani TA, Ntoumi F, Kock R, Dar O, Ippolito G, Mchugh TD, Memish ZA, Drosten C, Zumla A, Petersen E. The continuing 2019-nCoV epidemic threat of novel coronaviruses to global health - The latest 2019 novel coronavirus outbreak in Wuhan, China. Int J Infect Dis 2020;91:264-6.

2. General Office of National Health Committee. Announcement of the National Health Committee of the People's Republic of China (No. 1 in 2020). (2020-01-20) Available online: http://www.nhc.gov.cn/xcs/zhengcwj/202 001/44a3b8245e8049d2837a4f27529cd386.shtml

3. World Health Organization. Naming the coronavirus disease (COVID-19) and the virus that causes it. (2020-02-
11) Available online: https://www.who.int/emergencies/ diseases/novel-coronavirus-2019/technical-guidance/ naming-the-coronavirus-disease-(covid-2019)-and-thevirus-that-causes-it

4. Chinese Society of Radiology. Radiological Diagnosis of New Coronavirus Infected Pneumonitis: Expert Recommendation from the Chinese Society of Radiology (First edition). Chin J Radiol 2020. doi: 10.3760/cma. j.issn.1005-1201.2020.0001. [Epub ahead of print].

5. Jin YH, Chen B, Zhang JF, Dai Q, Yan K, Ye HH, Cai T, Zheng JJ. Novel coronavirus pneumonia epidemic prevention and control by chest CT. Modern Practical Medicine 2020;32:141-4.

6. Lin J, Yan K, Dai Q, Zhang JF, Zheng NH, Zhang S, Hu YR, Ye HH, Zheng JJ, Cai T. Retrospective study and thinking on prevention and control strategy based on COVID-19 cases in Ningbo city. Modern Practical Medicine 2020;32:147-9.

7. Zhang JF, Yan K, Ye HH, Lin J, Zheng JJ, Cai T. SARS$\mathrm{CoV}-2$ turned positive in a discharged patient with COVID-19 arouses concern regarding the present standard for discharge. Int J Infect Dis 2020. doi: 10.1016/ j.ijid.2020.03.007. [Epub ahead of print].

8. Zheng JJ, Zhang JF, Dai Q, Yan K, Lin J, Zhang HB, Hu BB, Zhao WH, Mao YC, Hu YR, Ye HH, Cai T. Exploration and practice of COVID-19 imaging reporting and data system based on chest CT. Zhejiang Medicine 2020;42:307-10.

9. Song Z, Xu Y, Bao L, Zhang L, Yu P, Qu Y, Zhu H, Zhao W, Han Y, Qin C. From SARS to MERS, Thrusting Coronaviruses into the Spotlight. Viruses 2019;11:59.

10. Wang C, Horby PW, Hayden FG, Gao GF. A novel coronavirus outbreak of global health concern. Lancet 2020;395:470-3.

11. General Office of National Health Committee. Diagnosis and treatment of novel coronavirus infection pneumonia (trial version 7). (2020-03-03) Available online: http:// www.nhc.gov.cn/yzygj/s7653p/202003/46c9294a7dfe4cef 80dc7f5912eb1989/files/ce3e6945832a438eaae415350a8 ce964.pdf

12. Fang $\mathrm{Y}$, Zhang $\mathrm{H}$, Xie J, Lin $M$, Ying L, Pang $\mathrm{P}$, Ji W. Sensitivity of Chest CT for COVID-19: Comparison to RT-PCR. Radiology 2020. doi: 10.1148/ radiol.2020200432. [Epub ahead of print].

13. Lee TH, Lin RJ, Lin RTP, Barkham T, Rao P, Leo YS, Lye DC, Young B; National Centre for Infectious Diseases COVID-19 Outbreak Research Team. Testing for SARSCoV-2: Can We Stop at Two? Clin Infect Dis 2020. doi: 
10.1093/cid/ciaa459. [Epub ahead of print].

14. Guo L, Ren L, Yang S, Xiao M, Chang D, Yang F, Dela Cruz CS, Wang Y, Wu C, Xiao Y, Zhang L, Han L, Dang S, Xu Y, Yang Q, Xu S, Zhu H, Xu Y, Jin Q, Sharma L, Wang L, Wang J. Profiling Early Humoral Response to Diagnose Novel Coronavirus Disease (COVID-19). Clin Infect Dis, 2020. doi: 10.1093/cid/ciaa310. [Epub ahead of print].

15. Ai T, Yang Z, Hou H, Zhan C, Chen C, Lv W, Tao Q, Sun Z, Xia L. Correlation of Chest CT and RT-PCR Testing in Coronavirus Disease 2019 (COVID-19) in China: A Report of 1014 Cases. Radiology 2020. doi: 10.1148/ radiol.2020200642. [Epub ahead of print].

16. Guan WJ, Ni ZY, Hu Y, Liang WH, Ou CQ, He JX, Liu L, Shan H, Lei CL, Hui DSC, Du B, Li LJ, Zeng G, Yuen KY, Chen RC, Tang CL, Wang T, Chen PY, Xiang J, Li SY, Wang JL, Liang ZJ, Peng YX, Wei L, Liu Y, Hu YH, Peng P, Wang JM, Liu JY, Chen Z, Li G, Zheng ZJ, Qiu SQ, Luo J, Ye CJ, Zhu SY, Zhong NS; China Medical Treatment Expert Group for Covid-19. Clinical Characteristics of Coronavirus Disease 2019 in China. N Engl J Med 2020. doi: 10.1056/NEJMoa2002032. [Epub ahead of print].

17. Zeng Y, Fu J, Yu X, Huang Z, Yin X, Geng D, Zhang J. Should CT be used as a screening or follow-up tool for asymptomatic patients with SARS-CoV-2 infection? Quant Imaging Med Surg 2020. doi: 10.21037/qims.2020.04.10. [Epub ahead of print].

18. Xu R, Du M, Li L, Zhen Z, Wang H, Hu X. CT imaging of one extended family cluster of corona virus disease 2019 (COVID-19) including adolescent patients and "silent infection”. Quant Imaging Med Surg 2020;10:800-4.

19. Zwirewich CV, Mayo JR, Muller NL. Low-dose high-resolution CT of lung parenchyma. Radiology 1991;180:413-7.

20. Jin S, Zhang B, Zhang L, Li S, Li S, Li P. Lung nodules assessment in ultra-low-dose CT with iterative reconstruction compared to conventional dose CT. Quant Imaging Med Surg 2018;8:480-90.

21. Christe A, Torrente JC, Roychoudhury K, Vock P, Roos JE. Accuracy of low-dose computed tomography (CT) for detecting and characterizing the most common CT-patterns of pulmonary disease. Eur J Radiol 2013;82:e142-e150.

22. Pan $Y$, Guan H. Imaging changes in patients with 2019nCov. Eur Radiol 2020. doi: 10.1007/s00330-020-06713-z. [Epub ahead of print].

23. Jin YH, Cai L, Cheng ZS, Cheng H, Deng T, Fan YP,
Fang C, Huang D, Huang LQ, Huang Q, Han Y, Hu B, Hu F, Li BH, Li YR, Liang K, Lin LK, Luo LS, Ma J, Ma LL, Peng ZY, Pan YB, Pan ZY, Ren XQ, Sun HM, Wang Y, Wang YY, Weng H, Wei CJ, Wu DF, Xia J, Xiong Y, Xu HB, Yao XM, Yuan YF, Ye TS, Zhang XC, Zhang YW, Zhang YG, Zhang HM, Zhao Y, Zhao MJ, Zi H, Zeng XT, Wang YY, Wang XH, for the Zhongnan Hospital of Wuhan University Novel Coronavirus Management and Research Team, Evidence-Based Medicine Chapter of China International Exchange and Promotive Association for Medical and Health Care (CPAM). A rapid advice guideline for the diagnosis and treatment of 2019 novel coronavirus (2019-nCoV) infected pneumonia (Standard version). Mil Med Res 2020;7:4.

24. Holshue ML, DeBolt C, Lindquist S, Lofy KH, Wiesman J, Bruce H, Spitters C, Ericson K, Wilkerson S, Tural A, Diaz G, Cohn A, Fox L, Patel A, Gerber SI, Kim L, Tong S, Lu X, Lindstrom S, Pallansch MA, Weldon WC, Biggs HM, Uyeki TM, Pillai SK; Washington State 2019-nCoV Case Investigation Team. First Case of 2019 Novel Coronavirus in the United States. N Engl J Med 2020;382:929-36.

25. Wáng YXJ. A call for caution in extrapolating chest CT sensitivity for COVID-19 derived from hospital data to patients among general population. Quant Imaging Med Surg 2020;10:798-9.

26. Li Q, Guan X, Wu P, Wang X, Zhou L, Tong Y, Ren R, Leung KSM, Lau EHY, Wong JY, Xing X, Xiang N, Wu Y, Li C, Chen Q, Li D, Liu T, Zhao J, Liu M, Tu W, Chen C, Jin L, Yang R, Wang Q, Zhou S, Wang R, Liu H, Luo Y, Liu Y, Shao G, Li H, Tao Z, Yang Y, Deng Z, Liu B, Ma Z, Zhang Y, Shi G, Lam TTY, Wu JT, Gao GF, Cowling BJ, Yang B, Leung GM, Feng Z. Early transmission dynamics in Wuhan, China, of novel coronavirus-infected pneumonia. N Engl J Med 2020;382:1199-207.

27. Liu J, Li S, Liu J, Liang B, Wang X, Wang H, Li W, Tong Q, Yi J, Zhao L, Xiong L, Guo C, Tian J, Luo J, Yao J, Pang R, Shen H, Peng C, Liu T, Zhang Q, Wu J, Xu L, Lu S, Wang B, Weng Z, Han C, Zhu H, Zhou R, Zhou H, Chen X, Ye P, Zhu B, He S, He Y, Jie S, Wei P, Zhang J, Lu Y, Wang W, Zhang L, Li L, Zhou F, Wang J, Dittmer U, Lu M, Hu Y, Yang D, Zheng X. Longitudinal characteristics of lymphocyte responses and cytokine profiles in the peripheral blood of SARS-CoV-2 infected patients. Med Rxiv 2020. doi: 10.1101/2020.02.16.20023671. [Epub ahead of print].

28. Xu Z, Shi L, Wang Y, Zhang J, Huang L, Zhang C, Liu S, Zhao P, Liu H, Zhu L, Tai Y, Bai C, Gao T, Song J, 
Xia P, Dong J, Zhao J, Wang FS. Pathological findings of COVID-19 associated with acute respiratory distress syndrome. Lancet Respir Med 2020;8:420-2.

Cite this article as: Zheng J, Zhang J, Yan K, Dai Q, Lin J, Zhang H, Hu B, Chen B, Cai T. Chest CT based Viral Pneumonia Imaging Reporting and Data System (VP-RADS): experiences of COVID-19 in Ningbo, China. Quant Imaging Med Surg 2020;10(7):1428-1440. doi: 10.21037/qims-20-587
29. Koo HJ, Lim S, Choe J, Choi SH, Sung H, Do KH. Radiographic and CT Features of Viral Pneumonia. Radiographics 2018;38:719-39. 